\title{
MGNREGA, power politics, and computerization in Andhra Pradesh
}

\section{Silvia Masiero \\ Diego Maiorano}

\begin{abstract}
: the link between e-governance and accountability of state administrations for service provision has been problematized in the literature to date. However, little is known about its application to anti-poverty programmes, of which public workfare schemes are an increasingly important subset. In this paper we fill the gap with a study of MGNREGA, India's largest workfare scheme, as it is being computerized in the southern state of Andhra Pradesh. A state-level information system was devised to ensure transparency of transactions, and hence combat the illicit diversion of the programme's funds to non-entitled recipients. But while doing so, the system carries a policy of centralization, which concentrates decision-making power in the hands of a limited set of actors rather than distributing it across the programme's stakeholders. In particular the Field Assistants, appointed officials responsible for the village-level management of the scheme, have direct control on the information inputted in the system, which reinforces their position of authority rather than challenging it in favor of greater empowerment of wageseekers. Furthermore, wage payments are traced by the information system till they reach the disbursement agencies, but are prone to capture in the "last mile" where workers collect their salaries, which results in greater vulnerability for them. As a result, MGNREGA workers are constructed by the new information system as sheer beneficiaries rather than active participants in the programme, which concurs to crystallizing power structures rather than resulting in wageseekers' empowerment. Lessons are drawn for other states currently computerizing their social safety nets.
\end{abstract}

Keywords: accountability, e-governance, anti-poverty policy, MGNREGA, India, Andhra Pradesh

\section{Introduction}


Over the last 10-15 years, workfare programmes have acquired increasing relevance as anti-poverty strategies. Narrative on these programmes has peaked in recent times, potentially as a result of globally increasing reliance on them as means to tackle poverty and unemployment (Devereux \& Vincent, 2010; Subbarao, Del Ninno, Andrews \& Rodriguez-Alas, 2013; Barrientos \& Hulme, 2016). In particular, the last decade has seen a sharp increase in the computerization of anti-poverty programmes, in all their phases from design to delivery. Computerization is designed to reduce leakage and ineffectiveness, and is hence widely seen as a desirable technical fix to the most fundamental problems affecting anti-poverty schemes (Bhatti, 2012; Muralidharan, Niehaus \& Sukhtankar, 2014).

In India, the Mahatma Gandhi National Rural Employment Guarantee Act (MGNREGA) is an integral part of the national anti-poverty agenda. By design, the programme provides a legal guarantee of 100 days of employment in public works per year to rural households who demand it. Though MGNREGA's positive effects on poverty reduction are widely recognized, wageseekers in the programme are found to be disempowered by diversion of funds, clientelistic allocation of work, and systematic delays in the scheme's wage payments (Pai, 2013; Mookherjee, 2014; Narayanan, Das, Liu \& Barrett, 2016). These problems severely hinder MGNREGA's downward accountability, as they result in systematic denial of entitlements and hence directly affect workers' livelihoods (Chopra \& Khera, 2012; Das, 2015).

Digital technologies have been increasingly taken up by Indian state governments to improve service provision, strengthen rural development, and increase effectiveness of anti-poverty programmes. With respect to MGNREGA, a pioneer state is Andhra Pradesh (AP), where a Management Information System (MIS) controls the scheme's functioning in all its phases (Murali, 2012). The system makes all MGNREGA transactions, from procurement to assignation of works to villages, visible on the Internet through the programme's website. Beyond technical change, this implies a shift in the distribution of information, which affects the politics of MGNREGA and its accountability to wageseekers.

Having been in place since 2006, the information system for AP MGNREGA provides a solid basis for us to ask, what is the relation between the adoption of e-governance and the accountability of MGNREGA to 
its workers? To unpack this we conducted a state-level case study, based on three field visits between November 2013 and September 2014. The study has involved actors responsible for AP MGNREGA (senior officials, district-level bureaucrats, state- and village-level implementers), software designers involved in its digitalization, wageseekers employed in MGNREGA works, social auditors and community volunteers. Reliance on the analysis of participants' narratives has been paramount in answering our questions, and has led to a clear picture of the systems' functioning and its implications for programme implementation. Interview data have been triangulated with notes from observation of the information system at work, social audits, press releases, and government documents on the programme.

Our findings can be classified in two clusters, referring respectively to design and implementation of the information system for MGNREGA in the state. From the point of view of design, the system's functioning is explicitly oriented to transparency of all transactions, as all MGNREGA operations are updated into a publicly accessible server in real time. All fund flows can be traced on the Internet, and the payment infrastructure is currently being integrated with biometric recognition of users by disbursement agencies. This results into a system in which transparency is used in a purposeful and systematic way, tailored to combat the illicit capture of funds flowing through the programme.

Yet, when it comes to implementation, workers' narratives problematize the extent to which the system makes the programme more accountable to them. Payments' processes, computerized only till funds reach the disbursement agencies, are then left in the hands of banks and post offices: this makes it difficult to trace the most crucial stage of the process, meaning the "last mile" in which payments are disbursed. Ten years after the inception of computerization, many workers still report late and incomplete wage payments, and greater information on fund flows has not resulted in fostering their bargaining power. Information displayed online is widely used by activists and community volunteers, but can hardly be accessed by the often illiterate and non-connected MGNREGA workers.

The paper hence contributes to unpacking the link between e-governance and accountability of the state for social assistance programmes, which some literature depicts as a tool-and-effect relation (Bhatnagar, 
2004). In the case of MGNREGA in Andhra Pradesh, technology reflects a political agenda that crystallizes the local hierarchies on which the programme has been constructed. In particular the Field Assistants, responsible for the village-level management of the scheme, can to an extent control the information inputted in the system: this reinforces their power position, rather than challenging it in favour of the systemic empowerment of wageseekers. Beyond the single case study perspective, what the study suggests is a problematic nexus between e-governance and accountability, directly informed by the political agendas underlying digitalization of anti-poverty programmes.

The paper is structured as follows. Section 2 describes the functioning of MGNREGA, and provides the rationale for studying its ongoing computerization. Section 3 illustrates the information system designed and implemented for MGNREGA in Andhra Pradesh. Section 4, focused on system design, explores the historical and political roots of the systems' orientation to transparency of transactions. Yet in section 5 implementation is explored, and the disconnections between the system's enactment and accountability to its users are identified. Section 6 concludes with lessons for other states computerizing MGNREGA and other social safety nets crucial to guaranteeing poorer people's livelihoods.

\section{Background and methods}

\subsection{MGNREGA: Implementation and Functioning}

Approved by the Indian Parliament on 23 August 2005, MGNREGA was implemented in 200 rural districts on 2 February 2006, and scaled up to the whole country in early 2008. The programme is based on the principle of non-excludability of the right to work, and enacts this principle by providing a formal guarantee of employment to all the residents of rural areas who demand it. By doing so it aims, at the same time, to improve the infrastructural development of rural areas, which benefit from public works (Khera, 2012). 
The scheme operates on a very large scale. In 2016-17, 2.34 billion person days of work were generated by the programme, covering around 51 million households, thus providing income for about 250 million people. ${ }^{1}$ The scheme has contributed to poverty reduction through positive impacts on consumption expenditure, intake of energy and protein, and asset accumulation (Liu \& Deininger, 2010), as well as food security, women's empowerment, financial inclusion and mental health of the affected households (MORD, 2012; Ravi \& Engler, 2014). MGNREGA is also found to yield positive effects on labour markets, through wage increases and reduction of distress migration to urban areas (Imbert \& Papp, 2015). The total cost of the scheme is just above $0.3 \%$ of India's GDP (Mookherjee, 2014). ${ }^{2}$

It is important to note that MGNREGA is an Act of Parliament, not just a government scheme, and this sets it apart from other Indian anti-poverty programmes (Jenkins \& Manor, 2017). This characteristic of the scheme makes it very difficult to withdraw, as employment guarantees provided by it are an integral part of national law. Importantly, the right to 100 days of employment in public works per year (or to an unemployment allowance, in case work cannot be procured) extends to all rural residents of India, not simply to those formally recognized as below the poverty line. This entails a mechanism that, while designed to facilitate self-selection of users, is weakened where MGNREGA wages are low, and where beneficiaries are not fully aware of the scheme's nature as a legal guarantee (Shankar \& Gaiha, 2013).

As in Jenkins \& Manor (2017, p. 3), the programme is demand-driven, meaning that "any person residing in a rural area can apply for work at their local government office". This confers a proactive role to wageseekers, making the scheme an occasion for them to exert direct agency by requiring and obtaining employment in public works. Furthermore the scheme is designed to involve village councils (panchayats) in its management, enhancing the degree of participation of local bodies in anti-poverty systems (Shankar \& Gaiha, 2013). Yet, since states hold a degree of discretionary power to adapt the programme to local needs and characteristics, diverse outcomes emerge in terms of the effective degree of decentralization and participation with which the scheme is implemented (Maiorano, 2014; Jenkins \& Manor, 2017).

\footnotetext{
${ }^{1}$ Full statistics are available on the national MGNREGA website: http://www.nrega.nic.in.

2 Critiques to the programme (e.g. Bhagwati \& Panagariya, 2014) find their core argument in the lower economic effectiveness of MGNREGA as compared to a cash transfers scheme. This point, while central in the ongoing debate, does not dispute the contribution to poverty reduction achieved by MGNREGA.
} 
Notwithstanding the widely recognized positive impact on India's rural poor, the system is affected by a range of issues at the national and sub-national level. One relates to diversion of funds outside the programme's supply chain, which reduces the amount of resources available to beneficiaries. ${ }^{3} \mathrm{~A}$ second problem pertains to the discretionary basis of allocation of MGNREGA work: though the programme works as a 'post-clientelistic' policy, personal connections still play a role in assignation of entitlements (Das, 2015; Maiorano, Thapar-Björkert \& Blomkvist, 2016). The issue is made more severe by shrinking budgetary allocations for MGNREGA by the central government, which impose additional financial constraints that limit the possibility to give work to anyone who demands it (Maiorano \& Das, 2015).

A third class of problems relates to wage payments, whose incomplete and delayed delivery affects a rising proportion of workers (Mookherjee, 2014). Payments should be generated for each work cycle in the scheme, and once a work cycle is complete, orders are submitted to disbursement agencies, in which wageseekers' accounts are credited with the payments due. Implementing agencies are hence separated from disbursement bodies, which increases the complexity of a supply chain already prone to capture. In fact, depriving MGNREGA wageseekers of timely payments significantly affects workers' capability to sustain their livelihoods through the programme, and may ultimately discourage them from seeking employment through the scheme (Bhatti, 2012; Muralidharan et al., 2014; Narayanan et al., 2016). ${ }^{4}$

To obtain a clear picture of MGNREGA, two more features should be considered. First, the programme is inscribed in a so-called "new rights agenda", a set of measures that deeply changed the nature of rightsbased policies by the Indian central government (Ruparelia, 2013). This new agenda includes, as of Jenkins and Manor (2017), measures such as the Forest Rights Act which provides new rights to traditional forest dwellers, and the Right to Education Act which makes schooling compulsory and at the same time entitles all children to attend school. By making the right to work universal and non-excludable, MGNREGA takes

\footnotetext{
${ }^{3}$ Drèze (2014) shows, however, that corruption is significantly lower in MGNREGA as compared to other workfare programmes, and has been declining over time.

${ }^{4}$ Over fiscal year $2014 / 15$, only 27.38 per cent of payments were disbursed within the prescribed 15 days, while more than 13 per cent were delayed by more than 90 days (Accountability Initiative, 2015).
} 
active part in this agenda, making employment guarantees a fundamental component of the pursuit of antipoverty action and socio-economic development.

A second feature of the programme is its variation between states, resulting in very different outcomes across the nation. It is the case that state-level political dynamics, including policy legacies and the nature of the social coalition supporting the ruling party, shape implementation on the ground, influencing the making of social policy (Deshpande, Kailash \& Tillin, 2017). That MGNREGA's implementation resents from political dynamics is argued by a substantial stream of literature (e.g. Shankar \& Gaiha, 2013, Maiorano, 2014; Jenkins \& Manor, 2017), and this angle entails a focus on state-level dynamics in the analysis of the programme. The state dimension is key to observing the ground reality of MGNREGA, and this has concurred to the choice of using a state-level study to answer our research question.

\subsection{Rationale and Methods}

Technical hurdles, and roadblocks in the delivery of entitlements, should be seen in the light of a broader debate on the politics of MGNREGA implementation. The recent debate has been informed by the programme's role in the space of social transformation, moving beyond simple provision of short-term benefits to recipients. Studying the structural effects of the programme, Carswell and De Neve $(2013,2014)$ highlight potential to enhance wageseekers' bargaining power towards high-class employers, making MGNREGA instrumental for transformative social protection (Devereux \& Vincent, 2010). In this perspective, if social assistance is intended as combating the root causes of poverty and vulnerability (Barrientos \& Hulme, 2016), the good functioning of MGNREGA concurs to tackling economic imbalances at their very basis.

The capacity of MGNREGA to reduce structural poverty is, however, a matter of discussion. Social anthropological understandings of the programme, grounded on in-depth study of its local politics, lead to observe that roadblocks to MGNREGA's effectiveness lie in structural power asymmetries, which prevent 
challenges to traditional class relations among the programme's actors. In particular, Pattenden (2011) suggests that the transformative social assistance agenda has not yet reached a sufficient degree of transformativity, as it does not advocate a systematic analysis of class relations. Similarly, Ghosh (2011) warns that development policies risk failure if they do not tackle the structural and systemic processes that generate poverty in the first place. Attention needs to be paid, as a result, to the specific social contexts through which poverty is reproduced over time, and to the ability of extant policies to deal with it.

In this light, some considerations are required on MGNREGA specifically. First, power asymmetry across actors in the programme is a known fact: the persistence of clientelism is a tangible sign of it, and is found also in states where the programme ranks well on most indicators (Das, 2015). Second, asymmetry is not neutral, but connotated along caste and gender lines (Pattenden, 2015; Maiorano et al., 2016), resulting in systematic inequalities in access to key means of social protection. As revealed by Pattenden's (2015) class-relational approach to the programme, issues seem to be of a structural, rather than incidental nature: power asymmetry reduces the bargaining power of workers, making them helpless towards resource diversion or payments that are missing or delayed for long times.

It is in this political perspective that the debate on e-governance in anti-poverty programmes should be placed. Computerized architectures, inscribed in the Indian anti-poverty system, are constructed as part of the solution to problems of effectiveness and accountability (Madon, 2009). As it enters anti-poverty schemes, technology should not be playing a sheer technical function, repairing existing hurdles and ensuring delivery of benefits. It should instead be entrenched in the political heart of the programme, hence affecting the power imbalances on which ineffectiveness is predicated.

The theme of power relations needs further unpacking in the ongoing debate on information and communication technologies (ICTs) for development. The link between ICT and accountability may not work as expected, and discrepancies may emerge between technology design and the reality for which systems are tailored (Heeks, 2002). Frequent failure of projects in ICT for development, affecting the public sector in particular, indicates the need to further problematize the link between e-governance and accountability 
of anti-poverty programmes, including workfare schemes like MGNREGA. This is arguably the main intellectual problematique relating to e-governance in the social protection space.

This leads us to ask, what is the relation between the adoption of e-governance and accountability of MGNREGA to its workers? This question is at the root of the study conducted here. MGNREGA's problems of fund capture, illicit allocation of works, and late/incomplete payments all contribute to generating an accountability gap between the programme and its users, which ICTs may contribute to bridging. However, social mechanisms linking e-governance to accountability of service providers are still unclear, and need to be elicited through dedicated observation of their functioning at the state level.

Our main source of data consists in 68 interviews, conducted in a phase (November 2013 - September 2014) in which the computerization of the programme had already become established. A first cluster of interviews was conducted with senior officials at AP's Rural Development Department, and aimed at forming a clear picture of MGNREGA in the state and the policy motivations lying behind computerization. A second one was conducted at Tata Consultancy Services, Hyderabad, and involved in-depth interviews with software designers and also practical demonstrations of the system's functioning. A third round was conducted with MGNREGA workers in Visakhapatnam district, where the scheme has been implemented since 2008. Our interviews with wageseekers have revolved around specific questions about their perception of technology in MGNREGA, their access to it, and the affordances related to its utilization.

Visakhapatnam covers a largely rural and tribal area of north Andhra Pradesh, whose internal diversity makes it representative of the variety of conditions experienced by MGNREGA workers within the state. The district is characterized by high rates of rural and tribal unemployment, and is included in the Indian Government's Backward Regions Grant Fund Programme since 2010. Selection of the study district was informed by the established presence of MGNREGA, as well as of volunteer associations that make the link between wageseekers and the institutions administering the programme. The presence of volunteer groups has been instrumental for a study of anti-poverty technologies, since these cannot easily be taken up by workers alone, and often need mediation by dedicated pressure groups. Working closely with the 
volunteer organizations, we have conducted research visits in six mandals of Visakhapatnam district, observing the system at work from the perspective of the workers operating its user interface.

The tribal context in which a substantial part of the research has been conducted deserves attention. Scheduled Tribes, recognized as a special category by the Indian Constitution, are among the most vulnerable socio-economic groups in the nation, and derive their main subsistence from basic agricultural activities conducted in land and forest. According to the 2001 Census of India, 61\% tribals in unified AP lived below the poverty line (Maiorano \& Buddha, 2015), and the economic fragility of such communities entails the need for state governments to adopt special terms for them. This calls for tailoring of anti-poverty programmes on the particular needs of tribal communities, and has led us to conduct interviews and observation in a tribal context whose approach to e-governance offered multiple cues for reflection.

Interviews have been informed by the concept of narrative interviewing as in Riessman (2008), in tune with the purpose of grasping the participants' lived experience of e-governance, as well as the policy rationale behind its implementation. Primary data have also been collected through group interviews at work sites, in which technologies have been collectively discussed by users as well as the mediating volunteers. To integrate such data, observations of the system at work have been conducted at Tata Consulting Services and in three Mandal Computer Centres, where Computer Operators illustrated their use of the system in managing MGNREGA operations. This has been complemented with secondary sources, in particular government documents on programme implementation and social audit reports produced by the State's social audit organization. ${ }^{5}$

\section{MGNREGA in Andhra Pradesh and its Computerization}

\footnotetext{
${ }^{5}$ Beyond research conducted for this paper specifically, the second author has led extensive work on MGNREGA in Andhra Pradesh, consisting of in-depth interviewing and participant observation of works and social audits in the districts of Vishakapatnam, Srikakulam, Guntur, Chittoor, Mahbubnagar, Karimnagar and Anantapur between 2012 and 2017. Part of this work has preceded the bifurcation between Andhra Pradesh and Telangana in 2014. This work has served to triangulate the data presented here, and to place observations in the broader context of MGNREGA.
} 
Andhra Pradesh is one of India's top spenders of MGNREGA funds, and has consistently ranked among the top providers of employment under the scheme. ${ }^{6}$ Below we detail the specificities of AP MGNREGA, and the properties of the digital system through which the programme is implemented.

\subsection{AP MGNREGA: Centralization and Transparency}

To explain the rationale behind the MGNREGA information system, it is crucial to grasp the historical and political context in which the system has been developed. Before the 2004 elections the incumbent chief minister, Chandrababu Naidu, was considered a model administrator by a variety of actors, including the press, business circles and international funding bodies. Naidu actively contributed to sustained economic growth and a very business-friendly environment, to the point of being referred to as the 'CEO of AP' (Suri, 2004). He also stressed the importance of ICTs for economic and social development, actively contributing to AP's rising reputation as a national hub for technology development.

After India's fiscal crisis in 1991, it was fundamental for state governments to commit to generate steady economic growth. Naidu did so, strongly emphasizing the importance of trade and openness to business for the state to thrive. However, his policies had systematic backlashes on the most vulnerable strata of the population, since investment in the private sector was not matched by equal attention to anti-poverty programmes and their funding. According to commentators, this resulted in 'the accentuation of poverty, growing income inequalities, unemployment and unabated farmers' suicides' (Suri, 2004: 5493).

Y. S. Rajasekhara Reddy, popularly known as YSR, was a prominent politician from the opposition, whose family was one of those that formed the backbone of the Congress party's organization during the anti-

\footnotetext{
${ }^{6}$ This was consistently true until 2012/13. From 2013/14 on, the ranking of Andhra Pradesh dropped significantly. While what caused the fall in employment generation is not clear, it is plausible that the agitation for the bifurcation of the state, occurred with the Andhra Pradesh Reorganization Act in 2014, affected the implementation of the MGNREGA too, as a result of the virtual paralysis of state administration post-bifurcation.
} 
colonial times (Maiorano, 2014). Leveraging the weaknesses in Naidu's popularity, he systematically accused Naidu of neglecting the rural world and the state's poor. He promised extensive welfare and ruraloriented programmes, following the principle that implementing workfare schemes successfully is an integral part of a populist politics (De Neve \& Carswell, 2011; Price, 2011). YSR won the 2004 elections by a large margin, promoting policy initiatives including a successful implementation of MGNREGA.

Yet, for the programme to have a chance of success, the scheme had to be implemented very differently from employment programmes implemented previously in the state, which were known for their high levels of leakage to the non-poor (Drèze, 2005). To maximize the new government's political credibility, corruption in welfare schemes had to be minimized, and specific monitoring systems had to be designed for social safety nets. In continuity with Naidu's regime, YSR was able to centralize power in his hands, with two objectives in mind: first, minimizing opposition through the centralization of decision-making with respect to both the hitherto faction-ridden Congress party and the administration of the state (Srinivasulu, 2009). Second, acquiring a significant degree of control over the state machinery (Maiorano, 2014), as a way to monitor the implementation of welfare schemes to convey a strong public image of corruption minimization.

The principles of transparency and centralization became visibly reflected in the state's management of MGNREGA. When it was launched, the state government institutionalized a civic monitoring mechanism based on social audits, through the creation of an independent society (the Society for Social Audit, Accountability and Transparency), that schedules and carries out audits in all villages on a rotation basis. Although the efficacy of this system has been questioned (Afridi \& Iversen, 2013), no other state has sought to implement systematic social audits as it is prescribed by the MGNREGA law. This is per se a deterrent against capture and misappropriation of funds, to be added to the fact that audits are now considered integral part of the MGNREGA model in Andhra Pradesh (Aiyar \& Samji, 2009).

As widely recognized, centralization surfaces more prominently in the Andhra model than in other states. In fact, the national MGNREGA law envisages full involvement of village-level elected institutions (Gram Panchayats) in the implementation of the scheme. On paper, Gram Panchayats should be responsible for 
numerous tasks, including selection of works and registration of wageseekers' demands for employment. At the same time though, the Andhra government has excluded Gram Panchayats from any meaningful role in implementation, delegating the management of MGNREGA works to appointed Field Assistants who are in charge of decision making at the village level (Maiorano, 2014).

A further peculiarity of Andhra Pradesh is that, differently from most other states, MGNREGA workers do not obtain and conduct work alone, but are organized to do so on a groups' basis. In every village, workers are divided into groups of $15-20$ members, headed by a leading actor referred to as a mate. As a result, all members get employment as a group rather than as individual workers, which at least on paper, should make it more difficult for Field Assistants to exclude wageseekers from accessing the programme. With this model, interactions between state administration and wageseekers are minimized, as the mate deals with all administrative procedures on the wageseekers' behalf.

\subsection{E-Governance for AP MGNREGA}

The implementation of MGNREGA in Andhra Pradesh is based on an information system that, since 2006, structures all operations in the programme. The system at the core of the programme has been developed and maintained by Tata Consultancy Services (TCS). This choice constitutes an anomaly, as in most Indian states, information systems for anti-poverty schemes are developed by the local offices of a state agency, the National Informatics Centre. A senior official explained the reason for this decision:

\footnotetext{
Experience and capabilities of TCS were a guarantee of reliability. The information system is the main way to guarantee transparency of the programme. (Senior Official, Rural Development Department)
}

Government narrative is adamant on the fact that, in Andhra Pradesh, the information system is an integral part of the functioning of MGNREGA. Its core purpose is that of enabling web-based accessibility (http://nrega.ap.gov.in) to all transactions in the programme, by computerizing its five core phases: 
Generation of works. Works are generated monthly for each mandal, on the basis of local needs and infrastructural development priorities. The information system allows the assignation of works, and calculates, on an automatic basis, the amount and nature of labour and capital required for each.

Procurement of materials. Procurement is carried out through e-tendering, an online procedure that allows every company to cast their offers and allows assignation to the lowest bidder. The construction of etendering has been aimed at eliminating corruption in the procurement phase, which was one of the most affected by illegal practices - as most bids, in the non-computerized system, were assigned on the basis of political connections. ${ }^{7}$

Measurement of works. Once works have been completed, outcomes are measured by Engineering Consultants, and payments are provided on that basis. Engineering Consultants and their staff use the information system to locate works, and to measure the extent to which expected outcomes have been achieved.

Processing of payments. Muster rolls (registers of workers employed in each work) are compiled at the work site, and uploaded weekly by the Mandal Computer Centre. Once measurement of outcomes has occurred, payment orders are uploaded online and sent to disbursement agencies. To collect their salary wageseekers need to visit the disbursement agency, or wait for a banking correspondent to visit their area. The system monitors the process till reception of payments by disbursement agencies.

Generation of reports. Since all operations described above are conducted through the information system, all of them are visible through the Andhra Pradesh MGNREGA website. On the same platform, reports are automatically generated for each district, mandal and constituency in which the programme operates. As summarized by one of the system's software developers,

\footnotetext{
7 Interview with a senior official, 30 August 2014.
} 
The rationale of the system is that of generating internal accountability. The initial idea was that of using the web to place MGNREGA in the hands of the citizens [...] the principle is that of full transparency of the programme, to clear corruption and make citizens' monitoring real. (Software Developer, Tata Consultancy Services)

Computerization of the payments' disbursement phase, while not yet homogenized at a state scale, is being led through two projects, Aadhaar-based recognition and a Smartcard Programme:

Aadhaar, also known as Unique Identification project (UID), is a national programme aimed at registering Indian residents through a 12-digit number and their biometric details. The Aadhaar database currently constitutes the biggest project of biometric identification ever conducted worldwide. In an increasing number of mandals, Aadhaar-enabled payments are operated, and registered wageseekers can therefore withdraw their wages on the basis of fingerprint identification. This is supposed to simplify the recognition procedure, and ensure that payments are made to genuine beneficiaries.

Smartcard Programme: beyond Aadhaar, Andhra Pradesh hosted a state-level project of independent biometric recognition, for payments of MGNREGA wages and social pensions. In 158 randomly selected locations, biometric smartcards have been assigned to entitled citizens to enable payments. Though the project has not been rolled out to the whole state, there seems to be strong potential for biometric recognition to enable more secure payments (Muralidharan, Niehaus \& Sukhtankar, 2014).

Built on the principle of transparency for empowerment, implicit in the information system, the payment infrastructure is complemented by biometric recognition at the level of disbursement agencies. This configures a carefully designed e-governance system, exceptional for a state whose general levels of ICT adoption in the public sphere are still quite limited. Seeking to understand how technology intersects with the politics of the programme, we present our findings in terms of system design and implementation. 


\section{Transparency and the Politics of System Design}

The system's focus on transparency of transactions, fitting the anti-corruption agenda set by YSR in the programme's early days, is rooted in the politics of programme implementation. The idea behind the system is that transparency should break the monopoly of information retained by implementing officials, thereby reducing the traditionally high discretionary power held by bureaucrats. As it emerged in interviews with senior officials at the Rural Development Department, the stated objective was that of reducing the influence of Members of the Legislative Assembly (MLAs) on the programme, to create a public image of political accountability. Many Cabinet ministers and MLAs reportedly resisted the introduction of transparencyenhancing technology, while YSR's rhetoric was very firm on the need for it, due to the instrumental value of transparency for the political agenda that he advanced. ${ }^{8}$

MLAs displayed three key interests related to MGNREGA. The first one was that of creating jobs in their constituencies, which was compatible with YSR's strategy. The other two interests, however, conflicted with it: one was that of diverting some of the scheme's funds to their patronized contractors, often owned by relatives or political clients, and in some cases by themselves. These can be involved in two ways: first, contractors can execute the works assigned to wageseekers, which is explicitly forbidden by the MGNREGA law. The information system makes this virtually impossible by monitoring the flow of funds and sending payments to beneficiaries' bank accounts, so that even if works are executed by a contractor, wages would still be paid to the beneficiaries listed in the official muster rolls.

Second, contractors can be involved in the procurement of works' materials, and MLAs put enormous pressures on the administration to assign procurement to their contractors. This was a minor problem before YSR's death, as the share of expenditure spent of materials amounted to less than $10 \%$ of the total. But

\footnotetext{
8 It should be noted that YSR's anti-corruption agenda was limited to welfare schemes and in particular to the MGNREGA, which played a central role in building his political credibility. In other spheres, such as the management of public revenues and the state's food security system, he allowed widespread corruption to occur, displaying sensibly lower levels of attention to the rigor of public procedures and their equality for all citizens.
} 
respondents' narratives agree on the view that after that, subsequent chief ministers were less able to control their MLAs, who constantly pushed for higher material expenditure. ${ }^{9}$ The e-tendering system, which assigns bids to contractors irrespective of their political connections, has been conceived to prevent this, hence creating a specific mechanism to reduce diversion in the phase of the programme where it was observed more frequently.

Of course, e-tendering does not automatically ensure that the bid assignation process will occur in a free and fair way. A senior official, interviewed in Hyderabad shortly after the implementation of e-tendering, reported frequent attempts of local counterparts (predominantly, bidders frustrated with the impartiality of the procedure) to tamper with the system, seeking ways to bypass the automatic assignation of bids. It is also true that technology, placed in a context characterized by a complex web of political connections, cannot per se eliminate the incentive of bidders to pursue their own interest of winning over other actors, and in principle local bureaucrats could find ways to bypass the automatized decision made by the system. Technology is, however, designed to minimize the discretionary power of bureaucrats, and it substantially increases the practical difficulty of tampering with it to appease individual requests.

The third interest displayed by politicians is that of controlling the programme through their network of officials in the state's administration. For example, MLAs can ask Field Assistants to provide more work to their voters than to supporters of the opposition. In this case YSR faced a difficult choice: he could have chosen to give Gram Panchayats the task of implementing the scheme, as prescribed by the MGNREGA law. This is the common praxis in other Indian states, and it would have meant empowering the councils' heads, the sarpanches, to provide jobs, significantly reducing the scope for discretion of the MLAs. ${ }^{10}$

YSR chose, however, a different route, that of implementing MGNREGA through Field Assistants. This option was more prone to interference by MLAs, who put pressures at various levels to appoint their men

\footnotetext{
${ }^{9}$ Interview, senior Rural Development Department official, Hyderabad, 9 December 2013.

10 Interview with the former Minister for Rural Development, Hyderabad, 5 August 2013. This was confirmed by the second author's field visits in Chittoor, Karimnagar, Mahbubnagar and Vishakapatnam districts. In every single village visited, we found that Field Assistants had important political connections.
} 
as Field Assistants: as powerfully summarized by a senior officer, 'all field assistant posts are political posts'. ${ }^{11}$ Yet in 2012, the Rural Development Department introduced a new feature in the information system, which made the appointment of Field Assistants automatic according to two criteria: all must be former MGNREGA workers, and the system selects three names according to their seniority, literacy, and number of days worked under the programme. This does not exclude the possibility that Field Assistants are co-opted into local power networks, but it reduces MLAs' discretion for influencing appointments.

It is important to observe the limits that automatic selection of Field Assistants encounters when operated in practice. It is true, on the one hand, that the system generates a list of individuals eligible as Field Assistants, and mandal level officials can only pick individuals that figure among the three top names of the list. But interviews conducted with street-level officials, even beyond the scope of the information system, have revealed the presence of cases in which, for instance, the three-name list is sent to the local MLA for vetting. In other cases, political connections have resulted in the three-name list being bypassed, and individuals being appointed as a result of their personal affiliation to local MLAs. As instances of clientelism persist, it is important to see the power of technology in its right proportions: while the automatic selection of Field Assistants adds a crucial layer of complexity to tampering, it still needs to be placed within the web of politics that characterize the programme at the state level.

It should be noted that in other Indian states, where Gram Panchayats are in charge of implementation, MLAs do not play such a significant role because the sarpanches, who are democratically elected, are strong enough to prevent them from interfering with the programme. ${ }^{12}$ However in Andhra Pradesh, the space for MLAs' interference was much more pronounced, and e-governance has hence been tailored in order to limit the perverse effects of this. As a result, MLAs are now being pushed to see the scheme as supplementary spending in their constituencies, which can enhance their popularity. ${ }^{13}$ Furthermore, MLAs'

\footnotetext{
12 This observation comes from the second author's extensive fieldwork in Rajasthan's rural areas in January-February 2014 and from conversations with scholars working on other states. See also Jenkins and Manor (forthcoming) for evidence regarding Rajasthan and Madhya Pradesh.

13 Interview, senior official, 5 August 2013.
} 
requests related to the MGNREGA are reported to be rather rare, as they know that little money can be earned at a high risk, and that computerization reduces the discretionary power of bureaucrats.

Resulting from a specific political context, system design physically enables greater centralization of powers in the scheme, a policy that is sustained by the transparency of the system's internal transactions. Yet users' narratives, explored below, provide a different angle on the enactment of e-governance.

\section{Computerization in Practice: Accountability of MGNREGA to Wageseekers}

How is system design related to accountability of providers to MGNREGA workers? To answer we observe, through wageseekers' narratives, the way in which the system's policy comes alive in practice. What emerges from these narratives, collected from workers and the volunteers assisting them, is a twofold problem, which affects both the accountability structure of MGNREGA and the mechanisms enabling wageseekers' capabilities to obtain information and exert their voice.

As noted above, Tata Consultancy Services' monitoring focuses on the implementing agency, and finishes just as payments are credited on wageseekers' accounts. A first cause for concern is that biometric authentication does not enforce downward accountability to wageseekers, but operates the inverse process, as it assures the state that recipients are genuinely entitled to payments (Khera, 2011). This also inspires the decision of paying wages on bank accounts rather than in cash, whose untraceable nature does not allow to ascertain the identity of the recipient and her entitlement to benefits.

The problem lies, though, in the other side of the accountability relation, that of the reliability of the institutions in charge of payments. As it emerged from wageseekers' narratives, it is exactly in the reliability of payments that the weakness of MGNREGA seems to lie: the problem of missing, incomplete and late payments has persisted over time, and computerization has not resulted into tangible changes in occurrence. In fact, workers do not trace a connection between centralized computerization and more 
reliable MGNREGA payments, and this results in perception of the system as unable to solve the main problem encountered. The lack of monitoring of disbursement agencies, the place in which wageseekers collect their payments, contributes to making wage payments uncertain, and is frequently mentioned as one of the factors that reduce effectiveness of the programme for beneficiaries.

Furthermore, biometric identification poses another problem, that of the recognition errors in which the system sometimes incurs. Issues of recognition, while minimized by programme staff, feature frequently in the narratives of wageseekers, and in those of volunteer organizations protecting them. For example, tribal workers interviewed at a work site openly displayed preoccupation about the system:

[Biometric recognition] very often does not work. If I go to the bank and it doesn't recognise me, I don't get paid, and nothing can be done about it [...] for five months, I could not collect any payments. This was not a problem when cash was paid. (Wageseeker, Narsipatnam)

Since [the biometric system] has arrived, citizens have to queue for many hours. If they are not paid, they have to go to the District Office, and hope to be luckier. Very often, going to the District Office only results in a day of work lost (Volunteer, labourers' organization, Visakhapatnam)

It needs to be added that tribal users, living in areas that often lack basic infrastructures and services, may need support when interfacing with technologies as new as biometric authentication and recognition. This special need, currently addressed by several organizations around the country, was not addressed with particular strength at the time of our fieldwork, leaving several interviewees to reveal mistrust and suspicion around such technologies, particularly towards their role in affecting access to entitlements under MGNREGA and other anti-poverty schemes.

To date, incidence of non-recognition of users through biometric devices has not been estimated in the state. Still, the extent to which this problem is reported in wageseekers' recounts is a major cause for concern, because non-recognition prevents the very reception of benefits through MGNREGA - and no back-up option, to use in case of failure, has been found at the disbursement agencies. Failure of biometric 
authentication, workers report, forces them to long trips to the district office, which may easily end in frustration. From these narratives, with respect to the area in which the research was conducted, technology seems to result in disempowerment of wageseekers, as it concurs to blocking the reception of MGNREGA wage payments instead of facilitating it.

Problems with downward accountability of disbursement agencies are matched by two more gaps, found at the level of the implementing agency. First, during works, wageseekers seem to have no means to ensure that their names have been included in the muster roll, the register on which payment generation is based. As reported in a group interview with wageseekers,

Whether one is, or is not, signed into the muster roll, depends on the FA [...] if one is not signed in as present, no payment can be made [to them]. [In each work], there is no way to know for sure that our names have been registered as present. (Worker, Visakhapatnam district)

Based on the narratives collected on the field, the picture that emerges is that high discretionality of Field Assistants and mates is a consequence of the centralized MGNREGA policy in the state. In such a system, the perverse dynamics of purposeful exclusion is not formally detected by the information system. The philosophy behind the technology, which matches every worker with a job card number, is designed to prevent the inclusion of 'ghost beneficiaries' in muster rolls, but does not prevent exclusion of genuine ones. As a result, while inclusion errors are tackled, exclusion errors are likely to remain unsolved, and this further weakens the accountability structure into place.

Secondly, payments are based on the measurements conducted by Engineering Consultants on works. If measurements reveal that, in a given work, expected targets have not been reached, payments will be lower than those initially determined. The problem here is that the system, while making measurements technically possible, does not guarantee their fairness, and hence there is still room for unjust practices in measurement, as explained by a member of a volunteer organization: 
The terrain is rocky, which makes it very difficult to dig in the first place. Still, workers have been digging it for months, but they keep being assigned to the same pond - where nothing is left to dig, they have hit rock bottom. The ECs know it, but no action is taken [...] workers have been paid 40-50 [Rs.] a day instead of 160 , because the measurement says they are less productive than they should be. (Volunteer, Narsipatnam)

Hence, disbursement agencies are not the only part responsible for missing payments of MGNREGA wages. Even the implementing agency presents gaps in accountability, which are found both in the construction of muster rolls, and in the measurements leading to determination of payments. The structure of MGNREGA in the state, flowing from the policy agenda that the system embodies, is not designed to achieve downward accountability to users, and seems therefore suboptimal in guaranteeing prompt payments.

The problem may in fact be running even deeper than that. For wageseekers to be able to claim their payments, two more mechanisms are needed: first, citizens need full information on their entitlements under the programme (e.g. wage determination, timings and conditions of disbursement). Second, the capability of exerting voice - lodging complaints, and having them attended in reasonable times - is needed in case of missing, incomplete, or late payments, so that grievances can be redressed.

With respect to information on entitlements, the picture is mixed. On the one hand, Andhra Pradesh is one of the states in which awareness of MGNREGA workers' rights is highest in India (Aiyar \& Samji, 2009), and evidence of awareness is consistently found in workers' narratives. In some cases, wageseekers even manage to obtain work in spite of lobbying action by big farmers, whose interests converge towards the minimization of MGNREGA work in their areas (Jakimov, 2014). A different matter is the capability of accessing work, which depends largely on Field Assistants: workers may still be subjected to exclusion, but their ability to demand paid work in MGNREGA is based on awareness of the programme.

On the other hand, an exception to the above is constituted again by tribal areas, where poverty levels are very high and literacy levels are low. In these areas, not only lacking awareness of entitlements is still a 
reality, but wageseekers are sometimes induced to see MGNREGA as offered by contractors, rather than as a right guaranteed by law. While the diffusion of such misleading narrative is difficult to estimate, the problem has been reported by community volunteers:

Many workers do not know it is their right to demand work [...] so, they do not know their entitlements. Without the intervention of volunteers, they would not at all know that they are due certain payments, at some specific regular times. (Volunteer, labourers' organization, Visakhapatnam)

Furthermore, even where awareness of the programme is high, issues persist with respect to information on exact amounts of MGNREGA wages. In most cases, workers are not aware of how payments are determined, and are therefore unable to claim the amounts due. This also makes the incidence of incomplete payments hard to measure, as wageseekers are not given precise estimates, which makes them unaware of the extent to which the process may be fair.

This brings us to the heart of the problem: has the system not been created exactly to make MGNREGA information fully accessible? On paper, it is so: yet, wageseekers are in large majority illiterate, and unable to access computers and other information technologies. Information provided by the system is not constructed for the wageseekers to access it: it is, instead, made available to organizations that are able to use data in a meaningful way. This includes the social audit organization discussed above, and the volunteer organizations which use the information system in their work. ${ }^{14}$ But information does not, at present, cater directly to MGNREGA's recipients, and this is a strong limit to its effectiveness.

Similarly, the system does not empower workers to lodge complaints, or to guarantee that their grievances can be redressed. Many workers reported the intention to lodge complaints, but were unable to identify an institutional means or mechanism to do so. Complaints do not only address missing payments directly, but

\footnotetext{
${ }^{14}$ Observation conducted at the Society for Social Audit, Accountability and Transparency, as well as at three different volunteer organizations engaging in protection of MGNREGA workers, has confirmed the frequent use that these organizations make of reports produced by the information system.
} 
revolve around the process through which they are determined, as in the above-mentioned case of unfair measurement:

It has been months since we reported the problem [of assignation of workers to the same pond, where nothing is left to excavate] to the RDD. Still, after months, we had no responses. We asked to classify the terrain [of this mandal] as rocky, which influences EC measurements, but even that request has never been listened to. (Volunteers, labourers' organization, Visakhapatnam)

To be sure, MGNREGA staff reported the presence of several redressal mechanisms, such as local call centres and programme offices to turn to, in case of any issues with benefits under MGNREGA. However, little evidence of awareness and/or usage of any form of grievance redressal has been found in wageseekers' narratives. As reported in a group interview at a work site:

They send us from one office to the other, till the APO [Additional Programme Officer] tells us to go [to complain] to the computer centre. Here, they [the Computer Operator] tell us that they cannot help, because it is the bank that decides on payments $[\ldots]$ it is very unclear who we should turn to. (Worker, Visakhapatnam district)

As it seems, the Computer Operator acts on a strategic nodal point of the programme, and enjoys full powers on a crucial stage of the payment process, that of uploading the muster rolls. His ineffectiveness in facing payment grievances is met with frustration: once again, in situations of this type, technology is viewed as disempowering, as the agent in charge of it is unable to address complaints effectively.

Crucially, the accountability structure examined here seems to derive directly from the centralized logic with which the programme is implemented. It is due to centralization if accountability structures focus chiefly on internal transactions, rather than on relations with wageseekers. Weakness of downward accountability mechanisms seems, therefore, a side effect of centralization, and a direct consequence of the top-down logic inscribed in the information system. Ultimately, the power politics implicit in the programme and in its 
implementation seem to be reinforced by the information system, which perpetuates the existing centralizing logic rather than challenging it in favour of greater empowerment.

It should be noted that workers' alienation, reviewed above through the voices of wageseekers, is not found solely in the problem of incomplete and late payments. It finds tangible manifestations in at least two more issues, which recur systematically in wageseekers' narratives. First, workers do not really have a voice in influencing the choice of works allocated to them: these should be decided by the Gram Sabha (an assembly consisting of all adult members of the Gram Panchayat), but commonly turn out to be chosen by the Rural Development Department. As noted by a worker group's leader,

[The workers' group] would rather engage in jungle clearance. This is the type of work that is needed in this area, because it is from jungle clearance that their households, their economy, would really benefit. But they are always assigned to irrigation works [...] because these are the works that they get from the government. [RDD] never asks which works would be better for them. (Worker, Visakhapatnam district)

This was again a tribal community, where jungle clearance was viewed as more important than irrigation, resulting in a scale of priorities that the Rural Development Department reportedly did not recognize. In the best cases reported, workers are consulted on the works that they perceive as most important, but it is still the Department that makes the final choice. It must be noted, however, that leaving the decision to the Gram Sabha would not by itself imply ensuring wageseekers' participation, as in many instances across India, the Gram Sabha depends strategically on the most powerful people within villages.

Another problem is found in the dynamics internal to groups, in which the discretionary power enjoyed by the mate is very high. Mates are in charge of voicing the group's stance when complaints are to be made, hence their role is characterized by responsibility rather than sheer authority. But it is undeniable that mates exert substantial power, as consistently reported in wageseekers' interviews:

The mate is very independent, and collaborates with the FA [...] if he wishes, the mate can withhold 
payments too, by not inserting names in the muster rolls [...] payments often depend on the mate's decision. (Worker, Visakhapatnam district)

Hence, MGNREGA workers in the state find themselves objectified not only by the problem of payments, but even by the groups' structure, in which they are de facto subjected to the mate. For how the programme is constructed, workers seem to be excluded from participation in all its main aspects, and an alienating process of objectification surfaces in payments, works' assignations process, and even in the internal dynamics of workers' groups.

To sum up, the picture emerging from the data seems to suggest that the centralized logic of MGNREGA in Andhra Pradesh has been thought out to enhance the effectiveness of the scheme. However this logic constructs wageseekers as passive beneficiaries of the programme, rather than as active participants to it. Rather than subverting existing power relations, the information system seems to embody a policy that crystallizes them, which is reflected in the programme's design and implementation. As it emerges from wageseekers' narratives, the system results in higher degrees of transparency, but does not result in the greater downward accountability that an effective check on the power of Field Assistants would entail.

\section{Discussion and Conclusion}

In this paper, the link between uptake of e-governance and accountability of anti-poverty programmes has been observed through the case of MGNREGA's computerization in Andhra Pradesh. Studying the information system related to it, we found that the systems' design carries an accountability structure that acts on the transparency of internal transactions, but not on the direct involvement of wageseekers. Our findings reveal the inscription of a specific policy agenda in e-governance, for which the historical phase and political context of information system implementation have been crucial. This problematizes the 'tooland-effect' logic in the relation between e-governance and accountability, as the technology-led promotion of a centralized system results in suboptimal levels of accountability to wageseekers. 
While based on a single workfare scheme, central to India's anti-poverty agenda, implications may be envisaged at a more general level, concerning the globally rising use of ICTs in social safety nets for poverty reduction. Adding to the rapidly expanding literature on this topic, we find that e-governance does not per se speed up existing accountability mechanisms, but seems, at least from the experience of computerization recounted here, to embody the assumptions and priorities inscribed in the state government's political vision. In the case of AP MGNREGA, transparency of transactions and centralization of responsibilities arise as core principles advanced by the government, and are reflected in an information system that is rooted specifically on their promotion. But the system also embodies the drawbacks of this agenda, relegating workers to a non-participatory role and making it impossible for illiterate wageseekers to access information without intermediaries.

If this is so, adverse class politics are not challenged by ICT implementation. This is because the information system is designed in such a way to consolidate roles, not to modify them in favour of greater empowerment of wageseekers. The vision of technology as a carrier of policy, found in Cordella and lannacci (2010), is hence reflected in our findings, as the information system embodies policy decisions made prior to computerization. The view of ICT as capable to subvert existing power relations is thus problematized, leaving room for a vision of technology as instrumental to enacting the will of the political actors behind it.

In turn, this problematizes the view of computerization as a desirable technical fix to the issues affecting delivery of anti-poverty programmes. As noted by Corbridge \& Srivastava (2013), the function of antipoverty programmes is largely developmental, and goes beyond the short-term task of transferring social benefits to their recipients. Social safety nets are a direct expression of development policy, and are functional to promoting the principles of social protection behind them (Sabates-Wheeler \& Devereux, 2007). Rather than being viewed as standalone technological units, digital artifacts hence need to be observed in continuity with the policy agendas that they put forward. 
Beyond conceptual contributions, three orders of practical implications emerge from the study. First, we have learned from wageseekers' experience that technical glitches, such as non-recognition of workers by biometric devices, may result in denial of benefits to entitled recipients. This is particularly crucial at the present day, as biometric recognition is becoming hegemonic in anti-poverty schemes worldwide (Gelb \& Decker, 2011). If this is the case, the perverse effects of failure in biometric recognition, and more at large in technology for authentication of beneficiaries, need to be tackled as a matter of urgent priority, because problems lying at the technical surface level may result in the actual disempowerment of beneficiaries.

Second, technical changes in anti-poverty infrastructure may be inspired by deep-seated aims of policy reform. In India, Aadhaar is becoming increasingly connected to the delivery of social benefits, a move supported by the Central Government's decision to enact deep reform of the anti-poverty infrastructure (Government of India, 2015). Rather than simply combating leakage, Aadhaar-based identification is now being used to enact a policy shift to cash transfers, to be implemented in the place of the subsidies that dominate the current national anti-poverty agenda (Khera, 2016; Bhatia \& Bhabha, 2017). If enforced, this move will result in the radical reconstruction of India's anti-poverty system, with deep consequences for the entitlements of current beneficiaries and for the ways in which these will be delivered.

As a final remark, ethical considerations emerge when intersecting technology adoption with anti-poverty programme delivery. Exclusion errors, predicated on non-recognition of entitled beneficiaries, remind of the importance of ensuring alignment between technical infrastructures and the reality lived by users. As Aadhaar enrolment is becoming increasingly crucial for social benefits, including MGNREGA wage payments, the ethical importance of ensuring smooth delivery of anti-poverty benefits to all entitled users cannot be overstated. This calls for more research on technologies that, beyond combating leakage, ensure the minimization of exclusion errors that deprive genuine beneficiaries of their entitlements.

MGNREGA is deeply entrenched in Indian anti-poverty strategies, both at the national and at the state level. The construction of better accountability structures, based on appraisal of existing drawbacks, can increase responsiveness of the programme to wageseekers, which is vital for them to access their entitlements as 
prescribed by the scheme. We hope that our suggestions, based on the case presented here, may be a useful basis to integrate e-governance in the pursuit of this objective.

\section{References}

Accountability Initiative, 2015, MGNREGS budget brief 2015/16, New Delhi: Accountability Initative.

Afridi, F., \& Iversen, V., 2013, 'Social audits and MGNREGA delivery: Lessons from Andhra Pradesh', India Policy Forum, pp. 1-47.

Aiyar, Y., \& Samji, S., 2009, Transparency and accountability in NREGA: A case study of Andhra Pradesh, New Delhi: Accountability Initiative, CPR.

Barrientos, A., \& Hulme, D. (Eds.), 2016, Social protection for the poor and poorest: Concepts, policies and politics, London: Springer.

Bhagwati, J., \& Panagariya, A., 2014, "Rural Inefficiency Act: Despite protests about diluting NREGA, the PM is right to confine it to 200 poorest districts", Times of India, 23 October 2014.

Bhatia, A., \& Bhabha, J., 2017, 'India's Aadhaar scheme and the promise of inclusive social protection', Oxford Development Studies, Vol. 45, No. 1, pp. 64-79.

Bhatnagar, S., 2004, E-government: From vision to implementation - A practical guide with case studies, New Delhi: Sage.

Bhatti, B., 2012, "Aadhaar-enabled payments for NREGA workers". Economic \& Political Weekly, Vol. 47, No. 49 , pp. $17-20$. 
Carswell, G., \& De Neve, G., 2013, Women at the crossroads: Implementation of Employment Guarantee Scheme in rural Tamil Nadu, Economic \& Political Weekly, Vol. 48, No. 52, pp. 83-89.

Carswell, G., \& Neve, G., 2014, 'MGNREGA in Tamil Nadu: A story of success and transformation?' Journal of Agrarian Change, Vol. 14, No. 4, pp. 564-585.

Chopra, S., \& Khera, R., 2012, 'Cutting delays in MGNREGA wages', Ideas for India, available at http://www.ideasforindia.in/article.aspx?article id=62.

Corbridge, S., \& Srivastava, M., 2013, 'Mapping the social order by fund flows: the political geography of employment assurance schemes in India', Economy and Society, Vol. 42, no. 3, pp. 455-479.

Cordella, A., \& lannacci, F., 2010, 'Information systems in the public sector: The e-Government enactment framework' The Journal of Strategic Information Systems, Vol. 19, No. 1, pp. 52-66.

Das, U., 2015, 'Does political activism and affiliation affect allocation of benefits in the rural employment guarantee program: Evidence from West Bengal, India', World Development, Vol. 67, pp. 202-217.

De Neve, G., \& Carswell, G., 2011, 'NREGA and the return of identity politics in western Tamil Nadu, India', Forum for Development Studies, Vol. 38, No. 2, pp. 205-210.

Deshpande, R., Kailash, K. K., \& Tillin, L. 2017. 'States as laboratories: The politics of social welfare policies in India'. India Review, Vol. 16, No.1, pp. 85-105.

Devereux, S., \& Vincent, K., 2010, 'Using technology to deliver social protection: exploring opportunities and risks', Development in Practice, Vol. 20, No. 3, pp. 367-379. 
Drèze, J., 2005, 'Loot for Work Programme', Times of India, 1 July 2005.

Drèze, J., 2014, 'Learning from NREGA', The Hindu, 23 August 2014.

Gelb, A., \& Decker, C. , 2011, 'Cash at Your Fingertips: Biometric technology for transfers in developing and resource-rich countries', Centre for Global Development Working Paper no. 253.

Ghosh, J., 2011, 'Dealing with 'The Poor'. Development and Change, Vol. 42, no. 3, pp. 849-858.

Government of India, 2015, 'Wiping every tear from every eye: The JAM Trinity number solution', Economic Survey 205-2016, http://indiabudget.nic.in/es2014-15/echapvol1-03.pdf

Heeks, R., 2002, 'Information systems and developing countries: Failure, success, and local improvisations', The Information Society, Vol. 18, No. 2, pp. 101-112.

Khera, R., 2011, 'The UID project and welfare schemes'. Economic \& Political Weekly, Vol. 46, No. 9, pp. $38-44$.

Khera, R. (ed.), 2012, The battle for employment guarantee, New Delhi: Oxford University Press.

Khera, R., 2016, 'MNREGA: Technology vs. technocracy'. Ideas for India, available at http://www.ideasforindia.in/article.aspx?article id=1599

Imbert, C., \& Papp, J., 2015, 'Labor market effects of social programs: Evidence from India's Employment Guarantee', American Economic Journal: Applied Economics, Vol. 7, No. 2, pp. 233-263.

Jakimov, T., 2014, 'Breaking the backbone of farmers': contestations in a rural employment guarantee scheme', Journal of Peasant Studies, Vol. 41, No. 2, pp. 263-281. 
Jenkins, R., \& Manor, J. 2017. Politics and the right to work - India's National Rural Employment Guarantee Act, London: Hurst \& Co.

Liu, Y., \& Deininger, K., 2010, 'Poverty impacts of India's national rural employment guarantee scheme: Evidence from Andhra Pradesh', Manuscript, University of Minnesota.

Madon, S., 2009, E-Governance for development: A focus on rural India, London: Palgrave Macmillan.

Maiorano, D., 2014, 'The Politics of the Mahatma Gandhi National Rural Employment Guarantee Act in Andhra Pradesh', World Development, Vol. 58, pp. 95-105.

Maiorano, D., \& Buddha, C. 2015. 'MGNREGA in Andhra Pradesh's tribal areas'. Economic \& Political Weekly, Vol. 49, No. 51, pp. 15-17.

Maiorano, D., \& Das, U., 2015, 'Is the MGNREGA fund crunch making the programme clientelistic?', Ideas for India, available at http://www.ideasforindia.in/article.aspx?article $i d=1497$

Maiorano, D., Thapar-Björkert, S., \& Blomkvist, H., 2016, 'The paradoxes of empowerment: gendering NREGA in the rural landscape of India', Development in Practice, Vol. 26, No. 1, pp. 127-134.

Ministry of Rural Development (MORD), 2012, NREGA Sameeksha, New Delhi: Oriental Blackswan.

Mookherjee, D., 2014, 'MNREGA: Populist leaky bucket or successful anti-poverty programme', Ideas for India, http://ideasforindia.in/article.aspx?article id=292.

Murali, A., 2012,. 'India: Technological innovation for effective Management Information Systems', World Bank Group, http://elibrary.worldbank.org/doi/pdf/10.1596/9780821389683 CH10 
Muralidharan, K., Niehaus, P., \& Sukhtankar, S., 2014, 'Building state capacity: evidence from biometric smartcards in India', National Bureau of Economic Research (NBER) Working Paper No. 19999, October 2014.

Narayanan, S., Das, U., Liu, Y., \& Barrett, C. B., 2016, 'The 'Discouraged Worker Effect' in Public Works Programs: Evidence from the MGNREGA in India', SSRN Working Paper, https://papers.ssrn.com/sol3/papers.cfm?abstract id=2882149

Pai, S., 2013, 'Delayed NREGA payments drive workers to suicide', Hindustan Times, 29 December 2013.

Pattenden, J., 2011, 'Gatekeeping as accumulation and domination: Decentralization and class relations in rural south India', Journal of Agrarian Change, Vol. 11, No. 2, pp. 164-194.

Pattenden, J., 2015, 'Class and social policy: The national rural employment guarantee scheme in Karnataka, India', Journal of Agrarian Change, Vol. 17, No. 1, pp. 43-66.

Price, P., 2011, 'Re-visiting policy and political behaviour in India with a view of the national rural employment guarantee act', Forum for Development Studies, Vol. 38, No. 2, pp. 197-203.

Ravi, S. \& Engler, M., 2014, 'Workfare as an effective way to fight poverty: The case of India's NREGS'. World Development, Vol. 67, pp. 57-71.

Riessman, C.K., 2008, Narrative methods for the human sciences, Thousand Oaks: Sage.

Ruparelia, S. 2013. India's New Rights Agenda: Genesis, promises, risks. Pacific Affairs, Vol. 86, No.3, pp. 569-590. 
Sabates-Wheeler, R., \& Devereux, S. , 2007,'Social protection for transformation', IDS bulletin, Vol. 38, No. 3, pp. 23-28.

Shankar, S., \& Gaiha, R. 2013. Battling corruption: has NREGA reached India's rural poor?. New Delhi: Oxford University Press.

Srinivasulu, K., 2009, 'Y. S. Rajasekhara Reddy: A political appraisal', Economic \& Political Weekly, Vol. 44, No. 38 , pp. 8-10.

Subbarao, K., Del Ninno, C., Andrews, C., \& Rodriguez-Alas, C., 2013, Public works as a safety net, Washington DC: The World Bank.

Suri, K., 2004, 'Andhra Pradesh: Fall of the CEO' in arena of democracy, Economic and Political Weekly, Vol. 39, No. 51, pp. 5493-5497. 